treatment or present following treatment overseas requesting further management. We frequently experience difficulties relating to the quality of information received regarding their management which makes follow up and ongoing treatment more challenging.

Methods Patients discussed in the multidisciplinary team meeting over a $3 \mathrm{yr}$ period who received treatment overseas were identified. The electronic patient record was reviewed for each patient to assess the quality of the information received regarding the clinical management (investigations, operative reports, chemotherapy and radiotherapy treatments). Pathology information received was assessed in terms of availability of reports meeting minimum dataset criteria or provision of pathological specimen blocks.

Results $15.1 \%$ of patients $(n=129 / 850)$ discussed by the MDT sought treatment overseas between 4/2015 and 3/2018. Patients travelled to 28 different destinations. Most commonly U.S.A(15.7\%), Philippines (15\%), UK(10.5\%) and Thailand (9.2\%). $60 \%$ of patients provided no or poor pathology information. $19 \%$ had no formal and $29 \%$ had inadequate clinical information regarding treatment received. Only 32.6\% $(n=42)$ provided adequate clinical and pathological information.

Conclusions The quality of information provided for patients travelling between different countries frequently falls below a level that is required for confident decision making regarding future management. Development of a recommended minimum dataset report to be used for such patients would be of significant value and is perhaps something that would appropriately be managed by the IGCS.

\section{EPV157/\#364 PATIENTS SEEKING GYNAECOLOGIC ONCOLOGY TREATMENT OVERSEAS: DOES IT MAKE A DIFFERENCE?}

${ }^{1}$ MT Alsayed ${ }^{*},{ }^{1} S$ Brich, ${ }^{2} \mathrm{H}$ Khaldi, ${ }^{1} \mathrm{~A}$ Magzoub, ${ }^{1} \mathrm{~A}$ Al -Ansari, ${ }^{3} \mathrm{~S}$ Alhyassat, ${ }^{4} \mathrm{H}$ Almalik, ${ }^{4} S$ Chandramouli, ${ }^{2} \mathrm{JJO}$ Herod. 'Hamad Medical Corporation, Women Wellness and Research Center, DOHA, Qatar; ${ }^{2}$ Hamad Medical Corporation, Women Wellness and Research Center, Doha, Qatar; ${ }^{3}$ hamad medical coorporation, Pathology, Doha, Qatar; ${ }^{4} N C C C R$, Oncology, Doha, Qatar

\subsection{6/ijgc-2021-IGCS.227}

Objectives All gynecologic oncology patients in Qatar receive treatment recommendations according to guidelines developed after reviewing international best practice (e.g., NCCN; ESGO; BGCS guidelines) by our multidisciplinary team (MDT). However, despite a highly-regarded and highlyaffordable or free national health service, many women travel overseas for treatment. We wished to investigate if the decision to travel resulted in any difference in treatment received, and whether that was of any benefit or harm to the patients.

Methods We performed a retrospective review of all patients discussed in the MDT meeting over a $3 y r$ period to identify those who received treatment overseas. The treatment received was reviewed for each case and compared with our MDT plan.

Results Approximately 1 in 7 (15.1\%) patients $(n=129 / 850)$ discussed by the MDT sought treatment overseas between 4/ 2015 and 3/2018. Patients travelled to 28 different destinations, most commonly; U.S.A(15.7\%); Philippines (15\%); UK $(10.5 \%)$ and Thailand(9.2\%). $25 \%$ of patients received different treatment to that recommended by our MDT. One had been referred to an overseas centre due to the unusual nature of her disease. Two patients opted for unrecognized and unproven treatment by alternative practitioners. Many patients were subjected to unnecessary investigations, surgery, chemotherapy or radiotherapy.

Conclusions Most women who travelled abroad received the same treatment to that recommended by the Qatar MDT. Commonly, where there was different treatment, we considered that treatment received was inappropriate according to our guidelines and international best practice. There was a tendency for patients to receive additional or unnecessary treatment after travelling.

\section{EPV158/\#447 THE IGCS PROJECT ECHO VIRTUAL TUMOR BOARD: REVIEW OF A PATHOLOGIST'S EXPERIENCE FROM THE FIRST 2 YEARS}

E Olkhov-Mitsel, A Plotkin*. Sunnybrook Health Sciences, Laboratory Medicine and Molecular Diagnostics, Toronto, Canada

\subsection{6/ijgc-2021-IGCS.228}

Objectives This project aimed to summarize the experience of a mentor pathologist in the IGCS ECHO project virtual tumor boards, which utilize case-based analysis of patients using videoconferencing technology to connect physicians in low resource settings with international mentors.

Methods All cases discussed by a single pathologist in the IGCS project ECHO virtual tumor board sessions from July 2019 to May 2021 were included. De-identified information was entered into a spreadsheet. Standard descriptive analysis was performed.

Results Since July 2019, 50 virtual tumor board sessions were attended by one mentor pathologist. One to three cases were presented each session. A local site pathologist was present in $60 \%$ of sessions. Pre-meeting case details and microscopic images were emailed to mentor for $94 \%$ of sessions and $64 \%$ of cases, respectively. Pathologic diagnosis was included for 91\% of cases. Mentor pathologist significantly contributed to the discussion of $71(86 \%)$ cases. Cases discussed were primarily cancers of the ovary $(n=30)$, cervix $(n=23)$ and endometrium $(n=10)$. Cancers of the uterus $(n=4)$, vulva $(n=4)$, vagina $(n=2)$, fallopian-tube $(n=1)$, germ cell tumors $(n=4)$, pregnancy-related malignancies $(n=3)$, and tuberculosis $(n=1)$ were also reviewed. Case discussions were focused on tumor morphology, grading and accurate classification, prognostic factors, differential diagnosis, immunohistochemistry, appropriate tumor sampling, and the value of cytology. Appropriate references were suggested for review.

Conclusions Participation of consultant pathologists in IGCS project ECHO virtual tumor boards significantly improves the quality of pathology data for clinical management and provides educational opportunities to physicians in low resource settings for better management of gynecological cancers.

\section{EPV159/\#479 ROLE OF PATHOLOGY CONSULTANT IN ADVANCEMENT OF DIAGNOSTIC ONCOLOGY IN UNDERSERVED COUNTRIES}

${ }^{1}$ A Plotkin*, ${ }^{2} \mathrm{~F}-\mathrm{IL}$ Lu. 'Sunnybrook Health Sciences, Laboratory Medicine and Molecular Diagnostics, Toronto, Canada; ${ }^{2}$ SHSC, Laboratory Medicine, Toronto, Canada

10.1136/ijgc-2021-IGCS.229 
Objectives Quality pathology assessment and reporting of gynecological cancers remains a significant challenge worldwide. Since 2019, the International Gynecological Cancer Society has been offering pathology support to underserved countries through monthly multidisciplinary conferences involving local and expert pathologists. We describe the format of this intervention.

Methods An expert pathologist joins conferences at 3-5 sites from underserved countries and discusses the clinical management of challenging cases selected by local gynecologic oncologists. Local and expert gynecologic surgical oncologists participate at each meeting, with occasional participation from radiation oncologists. Local pathologists from two sites consistently participate in these conferences; only these two sites submit pathology images and reports for review by an expert pathology consultant, who provides feedback on the accuracy of the diagnosis and the completeness of the pathology report. Other sites provide only a summary of the pathology diagnosis for discussion. All discussed cases are recorded in an Excel spreadsheet and include details on the management recommendations and the diagnostic pathology reports.

Results A pathology report remains a major challenge for local pathologists. The details important for tumor staging and management are often scarce or not present. The sites with involved local pathologists are starting to use International Collaboration on Cancer Reporting (ICCR) checklist for completeness of the report.

Conclusions Successful collaboration between local pathologists and international consultants is the first step towards improving the quality of pathology at many sites. The involvement of the local pathologists in the multi-disciplinary conferences and the collaboration with expert pathology consultants is crucial for the advancement of diagnostic oncology in underserved countries.

\section{EPV160/\#618 GLOBAL ASSESSMENT OF GUIDELINES FOR BRCA1/2 GENETIC TESTING: CALL TO ACTION IN HEALTH EQUITY FOR WOMEN AND FAMILIES AT RISK FOR HEREDITARY OVARIAN CANCER}

${ }^{1}$ BN Hughes*, ${ }^{2} \mathrm{JA}$ Rauh-Hain, ${ }^{1} \mathrm{TJ}$ Herzog, ${ }^{3} \mathrm{~S}$ Cummings, ${ }^{3} \mathrm{OL}$ O'Hanlon, ${ }^{3} \mathrm{D}$ Morah. ${ }^{1}$ University of Cincinnati, Cancer Center, Cincinnati, USA; ${ }^{2}$ University of Texas MD Anderson Cancer Center, Gynecologic Oncology, Houston, USA; ${ }^{3}$ Myriad Genetics, Salt Lake City, USA

\subsection{6/ijgc-2021-IGCS.230}

Objectives Personal and familial knowledge of genetic predispositions, especially BRCA1/2 deleterious mutations, have increasing implications in cancer prevention and outcomes. [1, 2] Lack of genetic testing is a barrier to global health equity. We explored the current state of genetic testing throughout the world and assessed regional variabilities.

Methods Guidelines for BRCA testing were found in publications, position papers, and online documents that outline testing criteria through a non-systematic literature review conducted by two certified cancer genetic counselors. Six categories for testing BRCA were created to capture the wide breadth of testing standards worldwide (table 1). [3-16]

Results Worldwide variability in BRCA testing persists even in regions with codified guidelines. Even regions with the economic structure to support widespread testing and clearly defined guidelines, (i.e. United States and United Kingdom) are undertesting for BRCA. Accessibility of these guidelines alone poses a regional difficulty not only for public
Abstract EPV160/\#618 Table 1 Categorical description of BRCA testing guidelines and regions which meet the criteria

\begin{tabular}{|c|c|c|c|}
\hline Category & Description & Region [3-16] & \\
\hline 1 & $\begin{array}{l}\text { Places/regions that have } \\
\text { formalized testing criteria - (i.e. } \\
\text { US with NCCN, ACOG, } \\
\text { USPSTF; UK with NICE) }\end{array}$ & $\begin{array}{l}\text { United States of America } \\
\text { United Kingdom } \\
\text { Australia } \\
\text { China } \\
\text { Canada } \\
\text { Wales/Australia } \\
\text { India } \\
\text { France } \\
\text { Netherlands }\end{array}$ & $\begin{array}{l}\text { Germany } \\
\text { South America } \\
\text { Mexico } \\
\text { Spain } \\
\text { Malasia } \\
\text { Norway } \\
\text { Colombia } \\
\text { Brazil }\end{array}$ \\
\hline 2 & $\begin{array}{l}\text { Places/regions that only do testing } \\
\text { on a research/clinical - no } \\
\text { defined national or professional } \\
\text { criteria }\end{array}$ & $\begin{array}{l}\text { Korea } \\
\text { Nigeria } \\
\text { Nepal } \\
\text { Saudi Arabia } \\
\text { Pakistan } \\
\text { Columbia }\end{array}$ & $\begin{array}{l}\text { Japan } \\
\text { Northern Africa } \\
\text { (excluding Libya } \\
\text { South Africa) }\end{array}$ \\
\hline 3 & $\begin{array}{l}\text { Places/regions where there is no } \\
\text { indication testing is done }\end{array}$ & \multicolumn{2}{|l|}{$\begin{array}{l}\text { Russia } \\
\text { Qatar }\end{array}$} \\
\hline 4 & $\begin{array}{l}\text { Places/regions that are exploring } \\
\text { population-based testing }\end{array}$ & \multicolumn{2}{|l|}{$\begin{array}{l}\text { United States of America } \\
\text { Canada } \\
\text { Australia } \\
\text { Srael }\end{array}$} \\
\hline 5 & $\begin{array}{l}\text { Inconclusive data / know doing } \\
\text { research but can't find criteria }\end{array}$ & \multicolumn{2}{|l|}{$\begin{array}{l}\text { Philippines } \\
\text { Finland } \\
\text { Sweden }\end{array}$} \\
\hline
\end{tabular}

knowledge and awareness, but uniform practice among healthcare providers.

Conclusions Global assessment of BRCA-directed guidelines are tremendously variable; therefore, formalized global guidelines are needed to expand access to testing, thereby improve health equity and patient outcomes. Lack of implementation even in Category-1 regions, highlights the need for greater awareness of guideline recommended care, and additional strategies to ensure optimized guideline adherence coverage.

\section{EPV161/\#265 CHALLENGES IN HISTOPATHOLOGICAL DIAGNOSIS AND CLASSIFICATION OF PRIMARY UTERINE SARCOMAS IN A REGIONAL TERTIARY ONCOLOGY CENTRE OVER A 5 YEAR PERIOD}

E Papadakou*, V Elliot. University Hospital Southampton, Pathology Department, Southampton, UK

\subsection{6/ijgc-2021-IGCS.231}

Objectives We aimed to determine clinicopathological characteristics of uterine sarcomas and compare the initial histological diagnosis at a tertiary oncology centre with the expert opinion from a specialist sarcoma unit.

Methods The histopathology electronic data base was searched using the key words 'Uterine' and 'Sarcoma'. All clinical and histological characteristics were collected retrospectively. The expert pathology diagnosis was also collected, where available and compared with the initial opinion offered by our department.

Results From January 2015 to January 2020 thirty seven patients were identified. Their median age was 61 years (2382). Eighteen patients $(48.6 \%)$ had Leiomyosarcoma, 6 (16.2\%) Low grade endometrial stromal sarcoma, 5 (13.5\%) High grade endometrial stromal sarcoma, 3 (8.1\%) Undifferentiated uterine sarcoma, 3 (8.1\%) Rhabdomyosarcoma and 2 Adenosarcoma (5.4\%). In 19 (51.3\%) cases a second expert review had been sought from a sarcoma unit. There was diagnostic agreement in almost $80 \%$ of the cases with the HGESS being the most challenging. $81 \%$ of patients underwent surgery and $7(18.9 \%)$ received chemotherapy or radiotherapy. 30 